\title{
PEMBUATAN KOMPOS DARI LIMBAH PADAT (SLUDGE) PABRIK PULP DAN PAPER
}

\author{
Maria Peratenta Sembiring dan Rozanna Sri Irianty \\ Jurusan Teknik Kimia Fakultas Teknik Universitas Riau \\ Kampus Binawidya J1. HR. Subrantas Km 12,5 Simpang Baru, Pekan Baru 28293 \\ Email : m_peratenta@yahoo.com
}

\begin{abstract}
One of the method to use pulp and paper mill sludge was convert it become a compost. This research result showed that time variation of compost have different physical and organic matter properties. In physical properties, 3 months of compost had $12.57 \%$ moisture content, while organic matter contain $10.56 \%$ carbon, $1.07 \%$ nitrogen, and $9.87 \mathrm{C} / \mathrm{N}$ ratio. For 4 months compost had $6.79 \%$ moisture content, $11.88 \%$ carbon, $0.91 \%$ nitrogen, and $13.05 \mathrm{C} / \mathrm{N}$ ratio. Nutrients content from both composts appropriate with the standard value of National Standarisation Body.
\end{abstract}

Keywords : Sludge, compost, moisture content, C/N ratio, nutrient

\section{PENDAHULUAN}

Industri pulp dan paper merupakan salah satu industri yang memberikan devisa yang cukup besar bagi negara. Berdasarkan data BPS $(2007)^{[1]}$, proporsi nilai ekspor pulp dan paper mencapai nilai tertinggi sekitar $40 \%$ dari total nilai ekspor industri kehutanan. Bahan baku yang digunakan umumnya berupa kayu alam, Acacia, dan Eucalyptus.

Dalam proses produksinya akan dihasilkan produk berupa pulp dan paper, dan tak kalah pentingnya akan dihasilkan limbah berupa lignin, sulfida, sludge, lime mud, boiler ash, lime dreg, dan pulp knot ${ }^{[2]}$. Jumlah limbah padat terutama sludge lebih kurang sepertiga dari jumlah seluruh limbah yang ada ${ }^{[2]}$. Limbah yang berasal dari boiler ash dan sludge akan menyebabkan pencemaran pada tanah, air tanah, dan ekosistem setempat.

Mengacu pada peraturan perundangan yang berlaku, yaitu UU No. 23 tahun 1997 tentang pengelolaan lingkungan hidup, maka sebaiknya limbah yang dihasilkan dikelola dan dimanfaatkan, yang diikuti dengan pengendalian pencemaran dan degradasi kualitas lingkungan serta sumber daya alam. Untuk itu diperlukan satu pemikiran dan penelitian untuk pemanfaatan kembali limbah tersebut yang telah diolah sehingga ramah lingkungan. Salah satu penelitian yang dapat dilakukan adalah mengolah limbah padat (sludge) menjadi kompos.

Jumlah limbah padat (sludge) yang dihasilkan pabrik pulp dan paper cukup banyak sehingga membutuhkan areal pembuangan (landfill) yang luas dan dalam jangka waktu lama akan menimbulkan dampak yang serius pada lingkungan ${ }^{[3]}$. Dari hasil analisa Balai Besar Pulp dan Kertas $(2004)^{[2]}$, diketahui bahwa sludge mengandung unsur-unsur antara lain nitrogen, fosfat, kalsium, magnesium, sulfur, besi, mangan, seng, dan natrium. Dengan adanya unsur-unsur ini, maka sludge dapat dijadikan kompos. Pada penelitian ini, kompos ini dibuat menjadi dua bagian berdasarkan umur pembuatan kompos yaitu kompos umur 3 bulan dan 4 bulan. Untuk mengetahui kelayakan kompos, maka dilakukan analisis kandungan unsur-unsur di laboratorium. Hasil analisis tersebut dibandingkan dengan nilai yang dikeluarkan oleh Badan Standarisari Indonesia $(\mathrm{SNI})^{[4]}$ untuk kompos.

Hasil penelitian ini menjadi salah satu cara mengatasi masalah limbah pada pabrik pulp dan kertas dengan membuat limbah padat 
(sludge) tersebut menjadi kompos. Hasil analisis kandungan kompos limbah padat (sludge) berada dalam batas ketentuan yang dikeluarkan oleh Badan Standarisasi Nasional (SNI) ${ }^{[5]}$ untuk kompos, maka kompos tersebut dapat digunakan pada tanaman seperti palawija.

\section{METODOLOGI PENELITIAN}

Adapun bahan dan alat yang digunakan: cetakan kompos $(2 \mathrm{~m} \times 2 \mathrm{~m} \times 30 \mathrm{~cm})$, cangkul, sekop, saringan dengan porositas $\pm 1 \mathrm{~cm}$, meteran, $\mathrm{pH}$ meter, peralatan gelas, neraca analitis, pipet, statif dan klem, penangas air, sludge, bahan nutrisi: kapur, urea, TSP, pupuk kandang, dan alat analisis Inductively Couple Plasma.

\section{Prosedur Kerja}

Limbah padat (sludge) diaduk sampai rata, kemudian dilakukan pembalikan tumpukan untuk mempertahankan kondisi aerobik. Proses pembalikan dan analisis fisik (kadar air, temperatur, warna, bau, dan $\mathrm{pH}$ ) dilakukan secara periodik selama proses pengomposan. Pada akhir pengomposan (yang divariasikan menjadi 3 bulan dan 4 bulan) dilakukan analisis laboratorium berupa: kandungan bahan organik (karbon
$[C]$, nitrogen $[N]$, perbandingan $C / N)$, unsur hara (kalium $[\mathrm{K}]$, phosphor $[\mathrm{P}]$, natrium $[\mathrm{Na}]$, kalsium $[\mathrm{Ca}]$, magnesium $[\mathrm{Mg}]$, aluminium $[\mathrm{Al}]$, besi $[\mathrm{Fe}]$, mangan $[\mathrm{Mn}]$ ) dengan menggunakan alat analisis Inductively Couple Plasma.

\section{HASIL DAN PEMBAHASAN}

Dari kualitas fisik kompos, pada semua bagian memenuhi nilai yang ditentukan Standar Nasional Indonesia (SNI) ${ }^{[4]}$ untuk kualitas kompos tetapi dalam jumlah yang minimum terutama pada kandungan unsur hara.

Bahan organik untuk nilai nitrogen $(\mathrm{N})$ $1,07 \%$ bila dibandingkan dengan nilai effluent sludge $0,19 \%{ }^{[5]}$, maka terjadi kenaikan jumlah nitrogen yang cukup besar yaitu 5,63 kali dan bila dibandingkan dengan nilai SNI $(>0,4 \%)$ dan nilai dari kebun percobaan Muara Bogor $(0,09 \%)^{[5]}$, maka dapat dinyatakan nilai nitrogen yang ada pada kompos slugde cukup baik. Namun demikian masih perlu ditambahkan pupuk anorganik untuk memenuhi kebutuhan tanaman karena tanaman (daun) memerlukan nitrogen $>3 \%$.

Diagram alir pembuatan kompos sludge $e^{[6]}$ :

Aerasi dengan cara

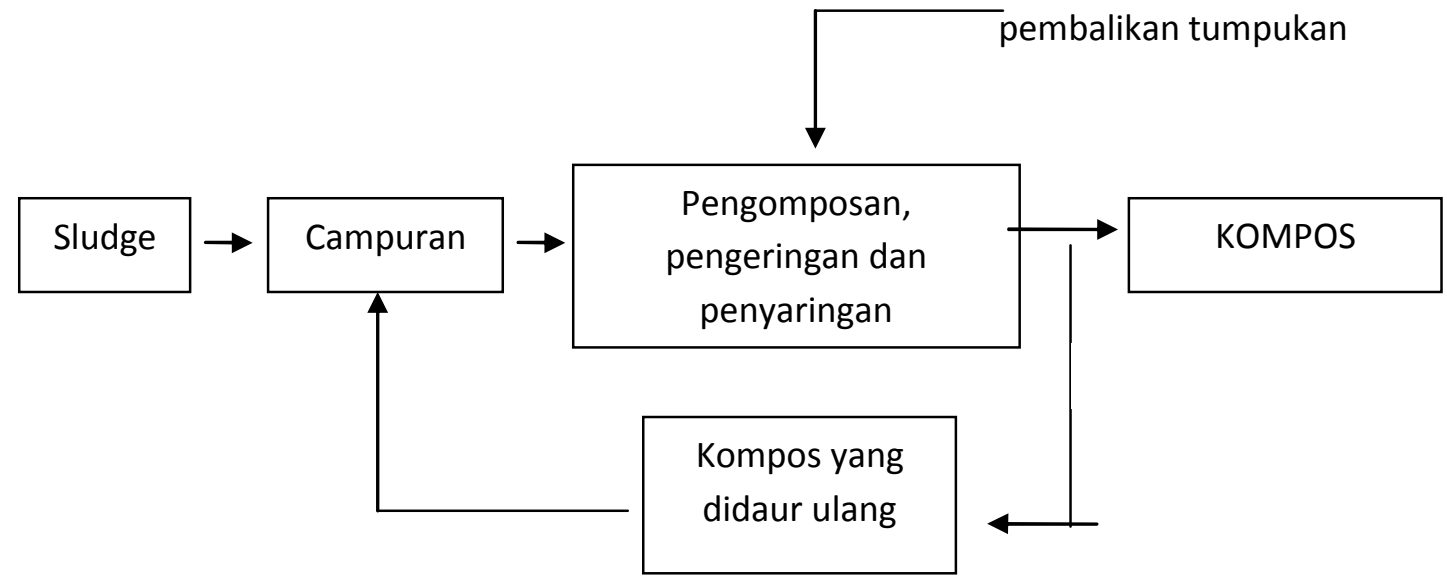

Gambar 1. Diagram alir pembuatan kompos 
Susunan dan letak tumpukan:

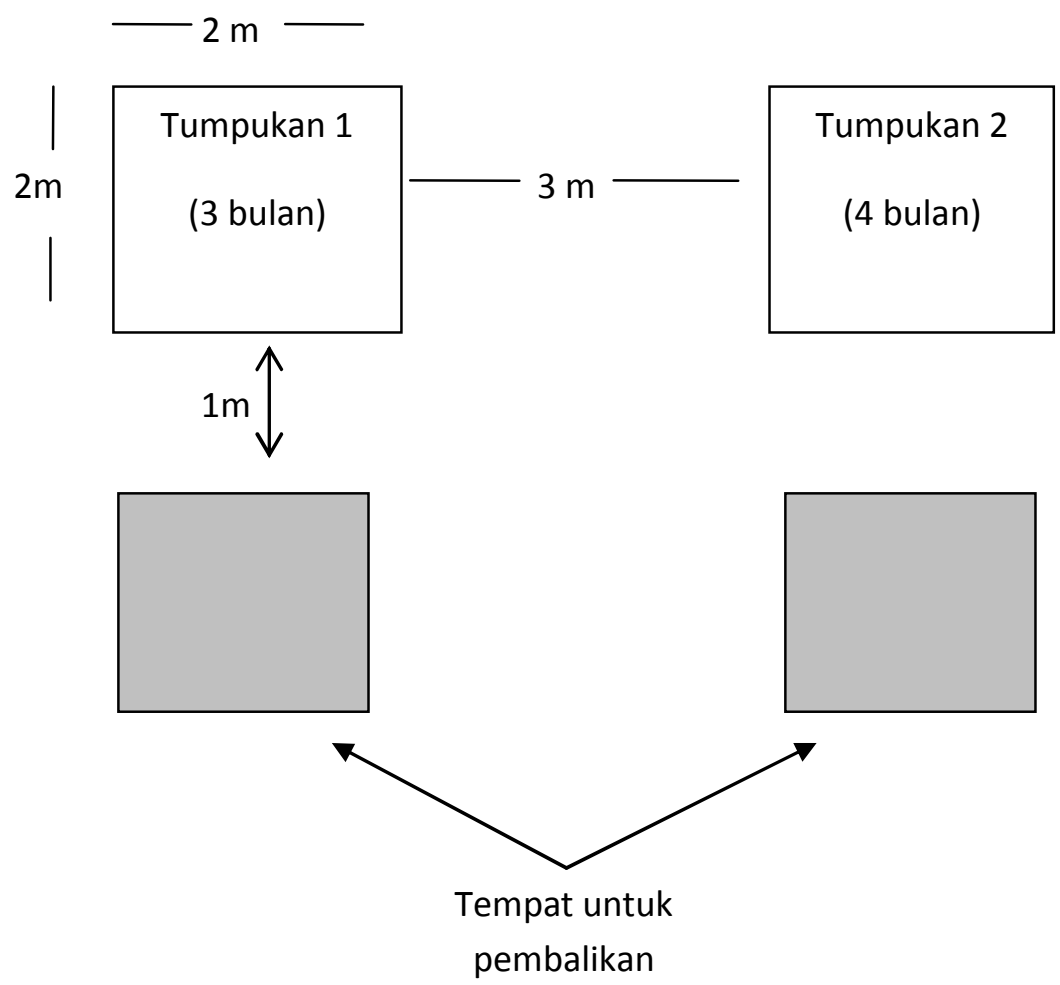

Gambar 2. Susunan dan letak tumpukan kompos

\section{Analisis Data}

\begin{tabular}{lll}
\hline No & \multicolumn{1}{c}{ Parameter } & \multicolumn{1}{c}{ Metode } \\
\hline 1 & $\mathrm{pH}$ & $\mathrm{pH}$ meter \\
2 & $\mathrm{C}$ organik & Walkley back \\
3 & $\mathrm{~N}$ & Kjeldahl \\
4 & $\mathrm{P}$ & Nitrat Perklorat \\
5 & Unsur Hara $(\mathrm{K}, \mathrm{Na}, \mathrm{Ca}, \mathrm{Mg}, \mathrm{Al}, \mathrm{Fe}, \mathrm{dan} \mathrm{Mn})$ & Inductively Coupled Plasma \\
\hline
\end{tabular}

Untuk nilai karbon (C) sebesar 11,88\% sudah melebihi nilai yang diperoleh dari kebun percobaan Muara Bogor yaitu sebesar 8,2\%. Jika dibandingkan dengan nilai SNI $>9,8 \%$, maka jumlah karbon pada kompos slugde sudah memenuhi standar.

Perbandingan $\mathrm{C} / \mathrm{N}$ yang diperoleh sudah memenuhi nilai SNI yaitu sebesar 9,87 (3 bulan) dan 13,05 (4 bulan). Perbandingan $\mathrm{C} / \mathrm{N}$ ini sangat penting pada proses pengomposan karena berhubungan dengan aktivitas biologis organisme. Jika nilai perbandingan $\mathrm{C} / \mathrm{N}$ terlalu tinggi, maka aktivitas biologis organisme menjadi berkurang. Untuk itu diperlukan beberapa siklus organisme untuk menyelesaikan degradasi bahan kompos sehingga waktu pengomposan akan lebih lama dan kompos yang dihasilkan memiliki mutu yang rendah. Jika perbandingan $\mathrm{C} / \mathrm{N}$ terlalu rendah, maka kelebihan nitrogen yang tidak dipakai oleh 
mikroorganisme tidak dapat diasimilasi dan akan hilang melalui volatisasi sebagai amoniak. Perbandingan $\mathrm{C} / \mathrm{N}$ yang ideal untuk proses pengomposan adalah 20-40 dan Perbandingan $\mathrm{C} / \mathrm{N}$ yang ideal setelah menjadi kompos adalah 10-20.

Kandungan unsur hara kompos yang diperoleh seperti kalium (K) sebesar 0,24\% dan fospat (P) $0,19 \%$. Nilai P yang diperoleh jika dibandingkan dengan nilai $\mathrm{P}$ pada effluent sludge $(0,0008 \%)$, menunjukkan kenaikan sebesar 23,75 kali. Jika dibandingkan dengan nilai SNI untuk kalium
$(>0,2 \%)$ dan fospat $(>0,1 \%)$, maka nilai dari kompos slugde ini terletak pada batas minimum sehingga perlu penambahan nutrisi.

Nilai kalsium (Ca) sebesar 1,16\%. Jika dibandingkan dengan nilai effluent sludge $(0,10 \%)$ telah mengalami kenaikan sebesar 11,6 kali. Tetapi masih jauh dari nilai maksimum yang ditentukan oleh SNI sebesar 25,5\%. Nilai magnesium $(\mathrm{Mg})$ pada kompos cukup baik yaitu sebesar $0,22 \%$ sehingga tidak perlu ditingkatkan karena kebutuhan tanaman hanya sebesar $0,15 \%$.

Tabel 1. Kandungan kompos sludge

\begin{tabular}{|c|c|c|c|c|c|c|}
\hline \multirow[t]{2}{*}{ No } & \multirow[t]{2}{*}{ Unsur } & \multirow[t]{2}{*}{ Satuan } & \multicolumn{2}{|c|}{ Kualitas kompos SNI } & \multicolumn{2}{|c|}{ Umur kompos } \\
\hline & & & Min & Maks & 3 bulan & 4 bulan \\
\hline & Kualitas Fisik: & & & & & \\
\hline 1 & Kadar air & $\%$ & - & 50 & 12,57 & 6,79 \\
\hline 2 & Temperatur & ${ }^{\circ} \mathrm{C}$ & & Suhu air tanah & 28 & 29 \\
\hline 3 & Warna & & & Kehitaman & abu-abu kehitaman & hitam \\
\hline 4 & Bau & & & Bau tanah & Bau tanah & Bau tanah \\
\hline \multirow[t]{2}{*}{5} & $\mathrm{pH}$ & & 6.8 & 7,49 & 7,24 & 7,28 \\
\hline & Bahan organik: & & & & & \\
\hline 6 & Carbon & $\%$ & 9.80 & 32 & 10,56 & 11,88 \\
\hline \multirow[t]{3}{*}{7} & Nitrogen & $\%$ & 0.40 & - & 1,07 & 0,91 \\
\hline & $\mathrm{C} / \mathrm{N}$ ratio & & 10 & 20 & 9,87 & 13,05 \\
\hline & Unsur hara: & & & & & \\
\hline 8 & Kalium (K) & $\%$ & 0,2 & $*$ & 0,235 & 0,24 \\
\hline 9 & Phosphat (P) & $\%$ & 0,1 & - & 0,19 & 0,22 \\
\hline 10 & Natrium (Na) & $\%$ & & & 0,424 & 0,73 \\
\hline 11 & Calsium $(\mathrm{Ca})$ & $\%$ & $*$ & 25,5 & 1,16 & 1,08 \\
\hline 12 & Magnesium (Mg) & $\%$ & $*$ & 0,6 & 0,22 & 0,17 \\
\hline 13 & Aluminium (Al) & $\%$ & $*$ & 2,2 & 0,012 & 0,013 \\
\hline 14 & Besi (Fe) & $\%$ & $*$ & 2 & 0,391 & 0,394 \\
\hline 15 & Mangan (Mn) & $\%$ & $*$ & 0,1 & 0,033 & 0,033 \\
\hline
\end{tabular}




\section{KESIMPULAN}

Dari hasil analisis, kualitas fisik kompos sludge berupa kadar air, temperatur, warna, bau, dan $\mathrm{pH}$ sudah memenuhi kriteria Standar Nasional Indonesia (SNI). Nilai perbandingan $\mathrm{C} / \mathrm{N}$ untuk kompos sludge berumur 3 bulan dan 4 bulan adalah sebesar 9,87 dan 13,05. Kandungan unsur hara kompos sludge kecuali unsur magnesium $(\mathrm{Mg})$ masih perlu ditambahkan untuk memenuhi kebutuhan tanaman.

\section{UCAPAN TERIMA KASIH}

Terima kasih diucapkan kepada Lembaga Penelitian Universitas Riau yang telah mendanai penelitian ini melalui dana DIPA Universitas Riau dengan kode kegiatan 10.06.01.2310.0531.521119.

\section{DAFTAR PUSTAKA}

1. BPS, Buletin statistik perdagangan luar negeri 2006, Badan Pusat Statistik, Jakarta 2007.

2. Anonim, Penelitian pemanfaatan bahan sisa pabrik, balai besar penelitian dan pengembangan industri selulosa, Bandung, 2004. Anonim, Penelitian Pemanfaatan Bahan Sisa Pabrik, Balai Besar Penelitian dan Pengembangan Industri Selulosa, Bandung, 2004.

3. I. Cooperben, Paper mill sludge and compos effluent on soil, University of Winconsin, Madison, USA, 2000.

4. Anonim, SNI 19-7030-2004, Balai Standarisasi Nasional, Jakarta, 2004.

5. Anonim, Penelitian pemanfaatan bahan sisa pabrik, balai besar penelitian dan pengembangan industri selulosa, Bandung, 2004. Anonim, Penelitian Pemanfaatan Bahan Sisa Pabrik, Balai Besar Penelitian dan Pengembangan Industri Selulosa, Bandung, 2002.

6. N. Djuarnani, Cara cepat membuat kompos, Edisi 2, Agromedia Pustaka, Jakarta, 2005. 